\title{
Opportunities and challenges of using socially intelligent agents: increasing interaction and school participation for children suffering from a long-term illness
}

\author{
Eva Mårell-Olsson \\ Department of Education, Umeå University, Umeå, Sweden, and \\ Thomas Mejtoft, Sofia Tovedal and Ulrik Söderström \\ Applied Physics and Electronics, Umeå Universitet, Umeå, Sweden
}

\begin{abstract}
Purpose - Children suffering from cancer or cardiovascular disease, who need extended periods of treatment in hospitals, are subjected to multiple hardships apart from the physical implications, for example, experienced isolation and disrupted social and academic development. This has negative effects long after the child's recovery from the illness. The purpose of this paper is to examine the non-medical needs of children suffering from a long-term illness, as well as research the field of artificial intelligence (AI) - more specifically, the use of socially intelligent agents (SIAs) - in order to study how technology can enhance children's interaction, participation and quality of life.

Design/methodology/approach - Interviews were performed with experts in three fields: housing manager for hospitalized children, a professor in computing science and researcher in AI, and an engineer and developer at a tech company.

Findings - It is important for children to be able to take control of the narrative by using an SIA to support the documentation of their period of illness, for example. This could serve as a way of processing emotions, documenting educational development or keeping a reference for later in life. The findings also show that the societal benefits of AI include automating mundane tasks and recognizing patterns.

Originality/value - The originality of this study concerns the holistic approach of increasing the knowledge and understanding of these children's specific needs and challenges, particularly regarding their participation and interaction with teachers and friends at school, using an SIA.
\end{abstract}

Keywords Artificial intelligence, Socially intelligent agent, Children, Health, Long-term illness

Paper type Research paper

\section{Introduction}

Children suffering from a long-term illness are subjected to multiple hardships. Apart from the physical implications of their condition, they can experience isolation, disrupted social and educational development and the psychological distress of dealing with problems far beyond their level of maturity. This is shown to have negative effects long after the child's recovery from the disease (van Dongen-Melman, 2000). Moreover, the concept of artificial intelligence (AI; i.e. intelligence demonstrated by machines) has become increasingly popular

(C) Eva Mårell-Olsson, Thomas Mejtoft, Sofia Tovedal and Ulrik Söderström. Published in The International Journal of Information and Learning Technology. Published by Emerald Publishing Limited. This article is published under the Creative Commons Attribution (CC BY 4.0) licence. Anyone may reproduce, distribute, translate and create derivative works of this article (for both commercial and non-commercial purposes), subject to full attribution to the original publication and authors. The full terms of this licence may be seen at http://creativecommons.org/licences/by/4.0/legalcode

Conflicts of interest: The authors declare no conflict of interest.

suffering from

a long-term

illness 
IJILT 38,4

394

over the last decade. One of many important aspects of AI is the development of artificial social intelligence, which is slowly being integrated into society in several ways. Dautenhahn et al. (2002, p. 1) define the field of socially intelligent agents (SIAs) as being "characterized by agent systems that show human style social intelligence". The authors also explain that SIA systems could be seen as "different from multi-agent systems that (1) are often only loosely related to human social intelligence, or use very different models from the animal world, e.g. self-organization in social insect societies, or (2) might strongly focus on the engineering and optimization aspects of the agent approach to software engineering". However, in human social activities, showing emotions is key for interactions. SIAs that can recognize a user's emotions and emotional expressions, as well as behave in a way that could be perceived as socially and emotionally appropriate, can make an important contribution to achieving a more "natural", believable and enjoyable human-computer interaction. Further, they explain that providing social artefacts as emotions and aspects of personality could be relevant in practical contexts, "in particular when (human) trust and sympathetic evaluation are needed, as in education, therapy, decision making, or decision support, to name only a few" (Dautenhahn et al., 2002, p. 6).

Furthermore, in healthcare, for example, SIAs could be designed to reduce loneliness in patients (Loveys et al., 2019). Furthermore, these systems can be built to support young and old patients psychologically through the immediate recommendation of measures in addressing their mental health, as well as assist their therapists in diagnosis (D'Alfonso et al., 2017). Research has, for example, proven the positive impacts of using robots to support children with autism and teach them how to interact socially (Dautenhahn, 2003; Amanatiadis et al., 2020). Thus, SIAs could impact healthcare and provide quality of life for patients, particularly because the number of patients in healthcare systems is increasing. The need for social interaction is even more noticeable among children suffering from a long-term illness who miss out on their ordinary school activities during long periods of treatment. Could an SIA assist children suffering from a long-term illness in coping with the various non-medical challenges of their situation? This paper aims to investigate the opportunities and challenges of using AI-based SIAs for enhancing the quality of life of children with a long-term illness with regards to a pedagogical perspective of social interaction and educational development. Further, the aim is to investigate and assess the non-medical needs of children suffering from a long-term illness, as well as research the field of AI and the use of SIAs in this context. In addition, the aim is to investigate the opportunities and challenges for tech companies in developing, implementing and producing AI products within this context for the market.

\subsection{Research questions}

$R Q 1$. What is required to support children with a long-term illness and their non-medical needs in order to enhance their quality of life regarding their social interaction and educational development?

$R Q 2$. How can AI-based SIAs be used in this context, and what are the social benefits?

$R Q 3$. What are the opportunities and challenges when developing, implementing and producing AI products for the market?

\section{Background}

Enjoyment of the highest attainable standard of health is one of the fundamental rights of every human being. The World Health Organization (WHO, 1946) defines health as "a state of 
complete physical, mental and social well-being and not merely the absence of disease or infirmity". It is therefore important to not only be treated for the impact of a disease but also receive support for quality of life during and after a disease to ensure the well-being of the individual. This includes treating the social and emotional effects. However, measuring quality of life as a score in an individual is far from easy. In the case of children suffering from a long-term illness such as cancer, thus far, no suitable index is available that is adapted to the specific situation of children (Mulhern et al., 1989). In many studies, researchers utilized the more general concept of health-related quality of life (HRQoL; e.g. Anthony et al., 2014; AlGamal and Long, 2016).

\subsection{Children and long-term illness}

When a child is diagnosed with a long-term illness (e.g. cancer or severe cardiovascular disease) and must stay in a hospital for long periods of treatment, they and their parents experience a multitude of challenges. Several issues must be addressed when trying to enhance a child's quality of life in such situations (e.g. enduring painful and/or frightening treatments). Enskär et al. (1997) found that when children who had recovered from cancer were asked what they did not like about being ill, they particularly referred to frightening and painful treatments such as receiving injections or taking pills and being anesthetized. Another issue concerns existential problems such as the fear of dying and the fear of relapse (i.e. why did I get sick and not someone else?). A child who falls ill is not capable of understanding that some things do not happen for a reason, and they might misunderstand the situation and believe they are being punished for misbehaving or that their parents were unable to protect them (Mattsson, 1972). Further, another issue is that when children are suffering from a long-term illness and need to stay in the hospital for an extended period, they lose access to their everyday life because they have been taken out of school and away from their friends. Being in this situation, it is important for the child's well-being to remain in contact with their school and classroom teacher even if they have been hospitalized. Also, when children fall ill, both their academic performance and social development suffer, even though they are way ahead of their peers in some respects (e.g. dealing with hardships and difficult questions about life and death).

\subsection{Psychological effects of long-term illness}

The psychological effects of long-term illness in childhood can affect the child's life even after recovery. Children who survive cancer, for example, have a significantly higher risk of developing post-traumatic stress symptoms later in life (Barakat et al., 1997). Even if children who have survived a serious illness are more prone to issues such as post-traumatic distress disorder, they may also experience an enhanced perceived quality of life. In fact, their general experience of school and life afterwards can be perceived as being better than those individuals who were not ill during their childhood. However, receiving this second gift of life can also transition into something called Damocles' syndrome. If children cannot recover their sense of security, they continue to live in fear of relapse, which decreases their general feeling of quality of life. One of the syndrome's symptoms is that you cannot be truly happy when you are living in constant fear. This condition has been noted in many survivors of childhood cancer. The most effective treatment for reducing a fear of relapse is cognitive behaviour therapy (Cupit-Link et al., 2018).

\subsection{SIAs in healthcare and education}

As mentioned in the introduction, AI has been slowly integrated into society in several ways for example, as an SIA that people can relate to as a companion (Kiron and Unruh, 2019). SIA 
IJILT 38,4

396 is referred to as a social machine that can communicate and interact with humans as well as understand and relate to humans in a personal manner (Breazeal, 2002). Dignum (2016) describes SIAs as systems whose behaviour can be interpreted by others as that of perceiving, thinking, moral, intentional and behaving individuals (i.e. as individuals who can consider the intentional or rational meaning of others' expressions) and that can form expectations about the actions of others.

In healthcare, humanoid robots are designed and often used by individuals at home or at healthcare centres for improving their medical conditions (Choudhury et al., 2018). In various areas of therapy, for example, the use of AI technologies is a burgeoning area that has seen important developments over the last decade (Dautenhahn, 2003; D'Alfonso et al., 2017; Luxton, 2014; Guerrero et al., 2016; Blusi and Nieves, 2019; Loveys et al., 2019). AI in the form of SIAs is already under study as a therapy, particularly for children with autism and children with Asperger's syndrome. Dautenhahn (2003) found that children interact with a social agent, in this case a robot, as if it were a real person or an animal. However, D'Alfonso et al. (2017) suggest that it is easier for some individuals to share their more private thoughts and questions with a machine than a person because the machine is perceived as being a more neutral agent. The use of SIAs in therapy with young people has been tested as an online interface for young people with psychological issues. In this particular case, the application used $\mathrm{AI}$ in the form of natural language processing to analyse the sentiment and wording when a patient described a problem. In this case, the SIA was able to instantly recommend action not only based on the described problem but also the emotions expressed by the patient in order to support them with their problems. Examples of such measures include mindfulness exercises, insight into why the problem occurred and so on (D'Alfonso et al., 2017).

\subsection{AI and education}

Research on socially engaging robots in education has focused on, for example, teaching processes, the incorporation of robotic-based engagement methods and how the robots might approach the effectiveness of human tutors or as peer learners (Belpaeme et al., 2018). In one study, Brown and Howard (2013) investigated the process of embedding social interaction within a humanoid-student learning scenario in order to reengage children during highdemand cognitive tasks. They found that by monitoring and acknowledging the beginning and end of tasks, the robot support was able to decrease idle time and maintain the subject's attention. However, the lack of understanding of the robot's actions among some of their informants were interpreted (by the informants) as the robot not giving any feedback. This, in turn, was perceived as an unpleasant learning experience (Brown and Howard, 2013). The positive emotional feedback from robot to child is, in general, important for the learning experience (Davison et al., 2021; Ahmad et al., 2019). In a review study on the potential of social robots in education and the technical challenges, as well as how the robot's appearance and behaviour affect learning outcomes, Belpaeme et al. (2018) found that the most popular robot of the analysed 309 study results was the Nao robot (i.e. a $54-\mathrm{cm}$-tall humanoid robot). Moreover, the Nao robot has almost become the de facto platform for many studies in the area of using robots for learning purposes. However, various robots became popular over time once a particular hardware model first became available. Further, Belpaeme et al. (2018) found that the use of social robots in education includes a variety of robots assigned to various roles - for example, the robot as a tutor or a teacher, the robot as a novice (i.e. allowing the student to take on the role of an instructor) or the robot as a peer or a learning companion for humans. Hence, social interaction requires the seamless functioning of a wide range of cognitive mechanisms; in addition, building artificial social interaction requires the artificial equivalent of these cognitive mechanisms and their interfaces. Further, they mean that this is 
why artificial social interaction is perhaps one of the most formidable challenges in AI and robotics (Belpaeme et al., 2018).

Nevertheless, the development of AI, specifically regarding SIAs, is also facing several challenges. Luckin $(2018$, p. 3) states that our world is increasingly being augmented by AI but that "there is a risk that our impoverished evaluation of human intelligence is leading us to over value the intelligence manifested in the latest technology and that we put at risk the future of humanity because we're not judging wisely the evidence of what is happening around us in our world". Tegmark (2017) stresses the importance of discussing the future of $\mathrm{AI}$ in relation to the role of humans regarding the limitations of our intelligence in making informed conclusions and how humans will use AI. Furthermore, Luckin (2018) argues that we could use AI in our continued endeavour towards intellectual growth, but it is important to focus on learning and what we learn when using AI in various ways. The author also emphasizes that the concept of learning is the reason why AI can be perceived as threatening. Further, the author argues for the importance of remembering, in that AI does not grow tired of learning and that it is always improving. Thus, we must also accept that it is crucial to develop and use AI in a responsible manner (Dignum, 2019).

Concerning the perceived self-efficiency in human beings, Bandura (1982) argues that higher levels of perceived self-efficacy are related to higher levels of performance. Luckin (2018) states that if we think about the essence of AI and how it is developed, the most important aspect is the design process through which the problem to be solved by AI has been clearly stated. However, trustworthiness is still a problem, and the author would not trust any teacher, AI or human who is unable to explain why they made a particular decision about something. Also, current AI systems are incapable of explaining their decisions because they have no metacognitive awareness. However, Dignum (2019) states there are major expectations regarding the potential of $\mathrm{AI}$ in helping solve many current problems and supporting well-being. However, there are also growing concerns about the role of AI in areas such as social inequality, job losses and warfare. In line with Luckin (2018), Dignum (2019) also stresses the importance of understanding what $\mathrm{AI}$ is, what it is not and what it can do. The positive use of AI must be ensured in ways that contribute to well-being and that align with our principles, priorities and values. Furthermore, the author believes we have to design ethically aligned AI systems that we can trust and that the following questions are important: why we design them, how to design them and who is involved in designing them.

In addition, the ongoing digitalization and rapid technological and societal changes also affect the education sector and impose new demands on education and how teaching and learning should be designed. In this field, the use of robots has a fairly long history, and, according to Serholt (2017), it is growing rapidly. However, the development of AI in the context of K-12 education has been criticised by Dreyfus and Dreyfus (1988), who raise concerns about developing intelligence traits in AI such as common sense, natural language and self-awareness. Luckin (2018) argues that it is not possible to develop an AI teacher that can relieve the human workload. However, it is possible to design AI tools that can support teachers in developing these elements of intelligence more effectively. It is therefore essential that trained teachers are included as key partners in the design of educational AI-based systems. It is these teachers who really understand what is to be taught, how their students learn and what types of systems are likely to work in most educational settings. Further, Luckin (2018) states that, in this increasingly AI-dominated world, it is of great importance that we provide education about AI because people need to understand enough about AI and human intelligence so as to effectively work with various AI-based systems. Moreover, everyone must be involved in discussions about what AI should and should not be capable of. In addition, an AI curriculum must be designed for the purpose of building the next generation of AI systems. According to Luckin (2018), the combination of other technologies such as virtual reality (VR), augmented reality (AR) and AI can support students with 
IJILT

38,4

398

physical and learning disabilities in engaging with virtual environments. This means participating in activities that would have otherwise been impossible for them. Also, AI might be used to interact with and respond to other users' actions in ways that feel more natural, even if it is in a virtual world. For example, AI might help children who have been hospitalized connect with their friends and school.

In a study by Hrastinski et al. (2019), teachers stated there is an extensive need for professional development if teachers are to become capable of using, for example, SIAs in K-12 classrooms for teaching and learning activities. Belpaeme et al. (2018) found that introducing social robots in the school curriculum also poses a logistical challenge. However, in the study by Hrastinski et al. (2019), the teachers had limited understanding of what AI is in general, and it was difficult for them to imagine how to use it in the classroom. However, they envisioned that AI and SIAs could be useful for individualising education. Hence, the increasing use of technologies in education in general and the benefits of SIAs in particular could be related to (1) research regarding hospitalized children suffering from a long-term illness and treatments and (2) to the fact that they often suffer from a perceived sense of isolation (Barakat et al., 1997). Could it be possible to help these children cope with the various non-medical challenges of their situation using SIAs in order to increase their virtual interaction and participation with school and enhance their quality of life by replacing a perceived sense of isolation with a sense of participation? What are the opportunities and challenges?

\section{Theoretical framework}

The theoretical framework used in this study is based on activity theory in which motives, goals, actions and operationalization are key starting points (Leontiev, 1986) with specific regard to the analysis process of the environment in which children suffering from a longterm illness are found when they have been hospitalized. Activity theory is a conceptual framework and has been used in psychology for analysing the work environment and, more recently, in the development of human-computer interfaces (Kaptelinin et al., 1995). Activity theory embraces an understanding and exploration of a context related to how social relations and materials, tools and intentions affect acting in various situations. Nardi (1996) explains that, in activity theory, it is important to investigate the role that a tool or artefact plays in everyday life - for example, in the case of this study, a child suffering from a longterm illness and hospitalization. Furthermore, Leontiev (1986) not only integrated the individual's actions but also group actions within a social system in which the individual is in focus (i.e. the child) but is understood in relation to an activity system (e.g. in this study, the context of children's hospitalization and the use of SIAs). Using activity theory as a theoretical framework helps make sense of the interplay between social relations, materials, tools and the stated motives in a situation (i.e. operationalization of the use of SIAs) in the context of hospitalized children. Activity theory also supports the understanding of the role of the artefact or, in this case, the use of an SIA, within the activity system (Nardi, 1996). Thus, activity theory is based on the notion that human thinking can only be understood in the context of meaningful, goal-orientated and socially-determined interaction between human beings and their material environment. It divides an environment and its interactions into motive, goal, actions and operationalizations (see Figure 1).

Figure 1.

Analysis criteria within an activity system

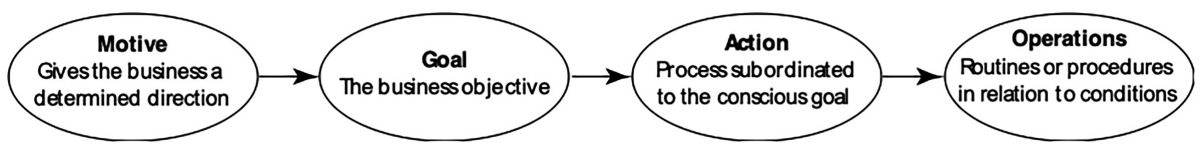


The concept of motive concerns the purpose of the situation and is the object of an entire activity system. It is human needs that motivate human activities. The concept of goal is the object towards which human activities are directed. The goal of an activity can often be divided into several sub-goals and organised into a hierarchy of goals and sub-goals. The concept of action concerns actions directed at achieving the goal(s). These actions can be external, in which the subject acts on the environment, or internal, in which the agent acts on itself. Operations do not have their own goals but adapt actions to the current situation and then implement them.

\section{Methodology and methods}

\subsection{Participants and study context}

A qualitative approach was adopted for this study in order to explore and expand the understanding of children's needs when suffering from a long-term illness and being hospitalized. This is in relation to how AI-based applications such as an SIA might cope with the various non-medical challenges of their situation and the opportunities and challenges they might offer for enhancing the children's quality of life with regards to a pedagogical perspective of social interaction and educational development.

Three sets of qualitative interviews with experts in various fields of knowledge were conducted in order to gather more knowledge about children's needs in relation to the use of AI-based SIAs. To take a holistic approach, this study applied a purposeful sampling method (Patton, 1990) in which three experts in three separate fields were selected for the study: (1) the housing manager for hospitalized children as an expert with practical knowledge of children's specific needs when suffering from a long-term illness; (2) a professor in computing science and a researcher in AI specializing in how individuals interact with AI and with expertise in the field of medicine and health as an occupational therapist; and (3) an engineer and developer at a tech company with experience in implementing cutting-edge technology in multiple fields on a commercial level and in the field of AI. The interviews adopted a semistructured form in order to capture the exploratory approach of this research study (Fontana and Frey, 2005). Each interview lasted about one hour and was recorded and transcribed verbatim.

Children suffering from a long-term illness could be described as a vulnerable group that must be handled with extra special care. As in this case, many studies have therefore used adults so as to shed light on children's perspective on themselves and their lives (Moinian, 2007). Illuminating a child's perspective from an adult's view means paying attention to what the consequences are for various political decisions or what experiences are contained in the diverse positions that children are allowed to take in a particular society (Halldén, 2003). Qvarsell (2001) describes that the concept of a child's perspective is used in various ways in debates about schools and preschools and sometimes from the viewpoint of professionals with experience working with children. Further, Halldén (2003) argues that the child's perspective becomes something beyond reproducing children's perspectives on various phenomena. The purpose of the interview with the housing manager, in this presented study, was to further the understanding of the special needs that children suffering from a long-term illness have with regards to their non-medical needs, such as social and educational development. The housing manager has years of experience working with children suffering from a long-term illness and is regarded as an expert within this area; thus, she represents the children's view on their needs (i.e. illuminating a child's perspective described above). The semi-structured interview guideline with the housing manager was constructed around challenges addressed in research regarding these children, such as (1) dealing with difficult, frightening and/or painful treatments, (2) existential problems, (3) losing context and (4) missing out on social and educational development. The interview also focused on what the 
IJILT 38,4

staff at the housing were doing to support the children who live there. The manager's firsthand experience of these children was valuable, particularly since it provided this study new insight not only into the struggles that the children faced but also the techniques the staff use and what they had developed to support these children.

To increase understanding from a researcher's perspective, the interview with the researcher (i.e. an expert in AI and specifically SIAs) focused on the opportunities and challenges when developing and implementing AI in general and SIAs in particular. In addition, the purpose was to investigate the current state of AI research and the direction in which it is heading, as well as examine the ethical aspects of developing an SIA that can interact with hospitalized children, for example. Also, the interview was intended to further this study's understanding of AI from a practical perspective, as well as regarding the current state of the art. The interview questions addressed to this expert were about what we can and cannot do with AI technology, where the research community is directing its efforts and how to drive technological development further. Several aspects were discussed in the interview such as the ability to build trust with humans, respond to emotions and motivate humans. It was confirmed that these capabilities are not possible at present but are currently under investigation.

The purpose of the interview with the engineer at the tech company was to investigate and further this study's understanding of previous research, as well as the results from the inerviews with the housing manager and the AI researcher. This shed additional light on the important considerations that exist when practically implementing "new" technology and obtaining a market perspective on using AI in current production. In addition, the purpose was to add the market perspective concerning how the market is very focused on trying out new technology, although there is the ever-present struggle of scaling up into products that are actually in the hands of end users.

\subsection{Data analysis}

The data collected in this study were first coded into emerging categories based on the key concepts of activity theory as the four nodes of motives, goals, actions and operation (Leontiev, 1986) and then into emerging themes within the three fields of expertise (see Table 1). First, the interviews were analysed concerning how the participants described the intentions and practical implementation within their specific field of expertise (e.g. motives, goals, actions and operations). The data were sorted in a table (see Table 1). The interviews were then used in comparison (i.e. triangulation) as a data set for analysing the emerging themes between the three fields (e.g. children's needs, SIAs [i.e. AI] and implementing and producing AI technology within the business sector). Thematic analysis (Ely, 1991) was used to identify key themes and emerging patterns within the framework of activity theory (Leontiev, 1986) so as to construct understanding and meaning from the collected empirical material. The iterative process could be described as encoding qualitative information to assist the researcher in their search for insight, and it includes two perspectives: "seeing" and "seeing as" (Boyatzis, 1998).

After analysing the data using the key concepts of activity theory within all three fields, a thematic analysis was conducted to extract knowledge from the data and produce comprehensive results. Creswell (2013) describes the process of "seeing as" as searching for repetitive patterns of meaning (i.e. significance) in qualitative data. Within this process, the various stages include (1) data reduction (coding), (2) data presentation (thematization) and (3) data summation, the latter in the form of conclusions and verification. Ely (1991) describes a theme as a definition of either utterances that all participants in a study make or as a single statement of an opinion that has great emotional or actual significance. The various stages of constructing meaning or seeing, as in this study, were made by searching for signs and 


\begin{tabular}{|c|c|c|c|}
\hline $\begin{array}{l}\text { Theoretical } \\
\text { concepts }\end{array}$ & $\begin{array}{l}\text { Fields of } \\
\text { expertise }\end{array}$ & Examples derived from the empirical data & $\begin{array}{l}\text { Children } \\
\text { suffering from }\end{array}$ \\
\hline \multirow[t]{3}{*}{ Motive } & $\begin{array}{l}\text { Children's } \\
\text { needs }\end{array}$ & $\begin{array}{l}\text { All children are to receive equal care } \\
\text { Ensuring that the period of illness is as easy as possible for the children } \\
\text { and their families }\end{array}$ & $\begin{array}{l}\text { g-term } \\
\text { illness }\end{array}$ \\
\hline & AI-research & $\begin{array}{l}\text { Enhancing the quality of life of humans, to make us generally happier } \\
\text { and our lives better }\end{array}$ & 401 \\
\hline & $\begin{array}{l}\text { Business } \\
\text { sector }\end{array}$ & $\begin{array}{l}\text { Overall interest in developing } \mathrm{AI} \text { in society due to its huge potential } \\
\text { within multiple fields }\end{array}$ & \\
\hline \multirow[t]{3}{*}{ Goals } & $\begin{array}{l}\text { Children's } \\
\text { needs }\end{array}$ & $\begin{array}{l}\text { Focus on what is healthy about the children instead of what is not } \\
\text { Keep their sense of normality as much as possible }\end{array}$ & \\
\hline & AI-research & $\begin{array}{l}\text { Enable machines to interact with us socially in order to develop from } \\
\text { where we are today }\end{array}$ & \\
\hline & $\begin{array}{l}\text { Business } \\
\text { sector }\end{array}$ & Identifying the right applications and perfecting the technology & \\
\hline \multirow[t]{5}{*}{ Actions } & $\begin{array}{l}\text { Children's } \\
\text { needs }\end{array}$ & $\begin{array}{l}\text { Providing accommodation in which families can live together in a } \\
\text { reasonably normal and comfortable environment }\end{array}$ & \\
\hline & & $\begin{array}{l}\text { Reminding the children of what they can do rather that what they } \\
\text { cannot do }\end{array}$ & \\
\hline & & $\begin{array}{l}\text { Reminding the children that there will be an end to their illness and a life } \\
\text { afterwards }\end{array}$ & \\
\hline & AI-research & $\begin{array}{l}\text { Keep entire factories of machines and no humans, into a society in } \\
\text { which AI-agents can operate between us }\end{array}$ & \\
\hline & $\begin{array}{l}\text { Business } \\
\text { sector }\end{array}$ & $\begin{array}{l}\text { AI works very well in confined environments on specific tasks, such as } \\
\text { learning to recognise patterns and predicting errors in systems, but is } \\
\text { less canable of recoonising different contexts and adanting to them }\end{array}$ & \\
\hline \multirow[t]{4}{*}{ Operations } & $\begin{array}{l}\text { Children's } \\
\text { needs }\end{array}$ & $\begin{array}{l}\text { Providing activity rooms with activities such as TV, climbing walls and } \\
\text { table tennis where families can meet and play } \\
\text { Arranging activities such as barbeques or games, where anyone who } \\
\text { wants to can join in }\end{array}$ & \\
\hline & AI-research & $\begin{array}{l}\text { Getting our pizza, cleaning the streets, becoming our companions } \\
\text { Gathering input through cameras, speech and text and drawing some } \\
\text { knowledge from the input } \\
\text { Interpreting human emotions on a low level }\end{array}$ & \\
\hline & & $\begin{array}{l}\text { Keeping data on a person and adjusting to their preferences } \\
\text { Working in environments using a specific set of rules and actors }\end{array}$ & $\begin{array}{r}\text { Table } 1 \\
\text { Examples of coding }\end{array}$ \\
\hline & $\begin{array}{l}\text { Business } \\
\text { sector }\end{array}$ & $\begin{array}{l}\text { Implementing AI-based products in the market is actually about having } \\
\text { people using the products in their private and working lives } \\
\text { Adaptation in a business working process }\end{array}$ & $\begin{array}{l}\text { and analysis using the } \\
\text { activity theory } \\
\text { theoretical framework }\end{array}$ \\
\hline
\end{tabular}

patterns on a more abstract level in participant utterances regarding what they explicitly or implicitly stated in their interviews. These iterative processes of constructing meaning of the empirical data through the lens of activity theory then shaped the emerging themes in the material, as presented in the Findings section.

\section{Findings}

The findings are divided into three emerging themes: (1) taking control of the narrative, (2) developing AI and SIAs for enhancing the quality of life for humans and (3) implementing and producing AI-based products. The first theme is about the children's overall situation when they were hospitalized, as well as their specific needs. The second theme applies to the research community and the development of AI-based SIAs. The third theme addresses the business and market perspective when implementing and producing AI products. 
IJILT 38,4

402

\subsection{Taking control of the narrative}

Enhancing the quality of life of children suffering from a long-term illness during the specific period of an illness must be made as easy as possible. However, there are many things that cannot be changed - for example, when a child must receive treatment and attend a hospital and it is not possible to shield them from the severity of the situation. Even when children are ill, they still need stimulation, interaction with their friends and school and stability, just like healthy children.

5.1.1 Keeping a positive attitude and focusing on the healthy part of life. According to the housing manager, when staying in accommodation near the hospital, it is important for these children to focus on what is healthy. This means distracting their focus away from the illness - for example, removing their focus on what they are no longer able to do and all the bad things that could happen. It is important to focus on what the children are able to do and what is good in life in order to maintain their motivation and increase their quality of life. According to the housing manager, focusing on the healthy parts of life could include the following: whether a child can still climb, make a phone call or participate in video sessions with their friends, interact with teachers and friends at school and so on. The importance of keeping a positive attitude is intended to help the children feel as happy as possible under the circumstances and combat their illness. Focusing more on what is healthy than on the illness itself also means reminding the children there will be an end to the illness and that much of what they left behind when they were admitted to the hospital will still be there once they are discharged. According to the housing manager, this is achieved not just verbally but also by letting the children maintain their activities and have contact with their existing school context, if possible, so as to prevent them from feeling too overwhelmed by the many changes that form part of a long-term illness. Trying to stay positive appears to be good for maintaining motivation. Like anyone else who experiences difficult times, it is important for children to have the opportunity to process their emotions and thoughts. A child may feel threatened if they get a disease for no reason at all and vulnerable because their parents cannot protect them from the disease or explain what is going on. They may also feel confused about being removed from their usual school setting.

5.1.2 Motivation and support. Children need motivation so they can handle the challenges of a severe illness. This can come in many forms. According to the housing manager, one way is to use incentives by giving the children something to look forward to after completing a difficult course of treatment. For example, "When you return, we can play this game". Another solution was to provide a certain type of accommodation - that is, an environment that does not resemble a hospital at all. This type of accommodation can provide a homely environment that is regarded as being as normal as possible and in which the children can simply have fun, engage in activities and participate in various activities (i.e. "somewhere to return to when the treatment is over").

5.1.3 Keeping the school context. Keeping the family together is important for children as they will need the support of those closest to them. The housing manager stated that it is also important for a child's well-being to keep their social school context, such as staying in touch with the activities in which they had previously participated before they became ill, as well as the teachers and friends at school whom they had to leave behind when they were hospitalized.

5.1.4 Networking with other children and families in the same situation. It is not only beneficial for children but for the whole family to meet other children and families in the same situation and at various stages of their illness. It is important for parents to be able to exchange their personal knowledge and experiences of the process with other parents. It is also important for the children to continue their social interaction and development by developing a new social context and playing with other children in the same situation. 
5.1.5 Digital storytelling. The housing manager stated that certain kinds of digital tools can help children take control of their situation by means of writing their own narrative, processing their thoughts and documenting their period of illness. This is in line with research highlighting the importance of focusing on what is healthy and what the children can do, namely taking control of their narrative and processing this through activities. According to the housing manager, children can use a digital tool as a diary and create a story about what their illness was like. Also, if they are able to take the data home with them later, it can be a helpful memory as they can continue the process of returning to normal life - for example, once they have returned to school and can talk to their friends about their experience.

Thus, creating opportunities for children to tell their own story will help them deal with and handle these issues by taking control of their narrative. According to the housing manager, one example is trying to make the child feel like a "hero" of their own stories, not a victim. This allows the child to experience all the feelings that might arise, both positive and negative, without letting the situation bring them down. It is also important to realize that children often prefer to process their emotions through play and activity, not through direct discussion. Thus, it could be important to take a more indirect approach while helping and supporting them to process their emotions, compared to an adult, for example. According to the housing manager, initiating activities such as painting and playing, which might allow the children to process their emotions and feelings during these activities, is a better option than introducing a direct discussion. Children's books and storytelling about the specific topics with which the children are dealing could also support this need.

\subsection{Developing AI and SIAs for enhancing the quality of life for humans}

According to the AI researcher, the overall motive for developing SIAs is to enhance humans' quality of life in order to make us generally happier and our lives better. The respondent stated that "we need to enable machines to interact with us socially in order to develop from where we are today, where we can keep entire factories of machines and no humans, into a society in which agents can operate between us - for example, getting our pizza, cleaning the streets and even becoming our companions". The AI researcher stated that developing machines that can understand social cues and adapt to contexts and environments is not an easy task but one that the research community is set on solving.

5.2.1 Current opportunities concerning SIAs. Over the last 30 years, researchers have been focusing on multiple fields within AI, such as machine learning, computer vision and knowledge reasoning and so on. These fields have been developed separately, and each field has useful algorithms and methods. There are systems that successfully recognize images, reasoning diagnosis systems and skilful walking robots. However, various technologies must be used in combination to create SIAs. According to the interviewed AI researcher, SIAs can currently be integrated into an overhead multi-agent system to make them mimic a human's way of adapting to situations and learning from interactions, although only to a minor extent. Further, the AI researcher explained that the following abilities have been developed today:

(1) Gathering input through cameras, speech and text and drawing some knowledge from the input

(2) Interpreting human emotions on a low level

(3) Keeping data on a person and adjusting to their preferences

(4) Working in environments using a specific set of rules and actors

Consequently, AI performs well, particularly with repetition and patient teaching. For example, an SIA will never get tired or bored with a child's questions and can give them all the suffering from a long-term illness

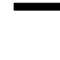


IJILT 38,4

404

time they need to learn, whereas a human teacher has limited resources in terms of time and stamina. It is also possible to add play in an SIA with the purpose of making learning more fun and interactive.

5.2.2 Current challenges concerning the development of SIAs. The AI researcher stated that challenges remain on all levels when developing SIAs, from the act of gripping a cup lightly with a robotic hand, to seeing and avoiding hitting a person or item of furniture when moving around, to properly engaging in conversation with a human with all of the context switching and social cues that this entails. Currently, AI can interpret expressions of human happiness, distress and so on to a certain degree. However, SIAs are limited in their capacity to meet and respond to these expressions in a satisfactory manner. Unlike humans, they are not yet able to analyse the character, context and personality of a person they meet and adapt their response to these parameters.

5.2.3 Ethical aspects. According to the AI researcher, there are several ethical aspects to consider when developing AI-based SIAs. Firstly, storing data that are gathered and stored by a SIA when interacting with and/or supporting a person must be taken into consideration. Sensitive personal data, such as data on individuals with disabilities or mental disorders, could be identified by the SIA and could therefore also be used against the person. Consequently, it is important to define the SIA's agenda. Also, the respondent stated that some of the knowledge gathering that is possible today could result in the implementation of an unintended control structure. Moreover, the AI researcher stated there are other ethical aspects to consider concerning children suffering from a long-term illness in relation to the use of SIAs. For example, an AI-based SIA must be developed to provide a trustworthy and accurate representation of the world and the child's social context. The AI researcher stated this is particularly important as children are learning about the world through interactions with their physical environment, including the SIA: "if a child hits a robot, for example, the child must enforce the social norm of not breaking things or causing harm by teaching the child that this type of behaviour is not acceptable. At the same time, it is also important to teach children that a socially intelligent agent is only an object, and that there is a difference between a socially intelligent agent, a dog and a human". Furthermore, "if the robot breaks, you don't have to grieve as you would grieve for a human". Thus, when helping children to express themselves and handle their emotions, an SIA is not capable of managing this in the same way as a human. However, a SIA could virtually interpret any input, log it as an emotion and give some sort of confirmation, and it could also log a child's emotions over time as part of the documentation if the child were to communicate this to the SIA. In such cases, a child and/ or their parents would have the opportunity to review the child's condition over a certain time frame.

5.2.4 The future of SIAs. The AI researcher stated that the research community is working on solving current challenges in the development of SIAs - for example, building trust with a human, building companionship with a human and managing various contexts, actors and environments competently by adapting to and learning from each interaction using knowledge from previous interactions. Further, she explained that AI researchers are attempting to solve these challenges and that their goal is to try and combine various AI technologies into the development of a true SIA. Moreover, the AI researcher explained that researchers have developed methods for solving these issues so that SIAs can work among us, cooperate with us and perhaps even be our companions.

\subsection{Developing, implementing and producing AI-based products}

There is an overall interest in developing AI in society due to its huge potential within multiple fields. However, there are still certain challenges in identifying the right applications and perfecting the technology. When transferring a concept developed by the research 
community to the business sector, many other problems emerge when transforming it into something people can use on a larger scale. When interviewing the employee of the tech company about the state of $\mathrm{AI}$ in the market, he stated that "while $\mathrm{AI}$ is currently an emerging trend in the tech industry as many people are able to see its potential, its implementations are not yet universally used". The respondent stated that the technology on the market needs to be further developed in order to become transformed into more general products to a greater extent. He also stated that AI works very well in confined environments on specific tasks, such as learning to recognize patterns and predicting errors in systems, but is less capable of recognizing different contexts and adapting to them. The employee of the tech company also explained there is a need for culture change in a company if the technology is to be incorporated as desired, especially if it is to be on a larger scale. Here, the employee of the tech company means that implementing AI-based products in the market is actually about having people use the products in their private and working lives. For example, an employee could be concerned that a product might make them unemployed because it has taken over some of their tasks, whereas they may actually get the time to perform other tasks to which they are more suited, such as meeting and interacting with people. The employee of the tech company also stated how there might have to be adaptation in a business work process - a process that employees may have been using for many years. When trying to convince employees to use new technology, it is also important to assess the existing culture at the company when a decision is made to introduce new technology.

\section{Discussion and conclusions}

In this study, three separate interviews were conducted in three fields, with an expert within each field trying to adopt a holistic approach. This study also investigated their experiences concerning the opportunities and challenges of using AI-based SIAs in enhancing the quality of life of children with a long-term illness, particularly with regards to focusing on avoiding a perceived feeling of isolation and increasing the children's participation and interaction with teachers and friends at school. Further, the aim was to investigate the non-medical needs of children suffering from a long-term illness, as well as research the field of $\mathrm{AI}$ and the use of SIAs in this context. Also, this study aimed to investigate the opportunities and challenges of implementing and producing AI products by tech companies within the business sector. This study only involved a small number of participants, which naturally made it impossible to make generalizations. However, each interviewee was an expert within their field. The interviews lasted for around $90 \mathrm{~min}$. Analysing the empirical material based on activity theory and thematic analysis was regarded as particularly useful for the first interview, in which the environment of children suffering from a long-term illness and their needs was investigated. Regarding the analysis process for the other two interviews, it was decided to partially combine the use of activity theory in particular with a more general analysis of the current market. This was in order to obtain information and map the extent of developments in the field of $\mathrm{AI}$ and, more specifically, the field of SIAs, as well as the opportunities the technology can offer. The employee at the tech company stated that when building systems such as AI and SIAs that could be designed to carry out tasks currently performed by humans, his company noted that a number of employees could become worried about losing their jobs, or the company concerned might not yet possess a culture that is capable of accepting this kind of technology. This is in line with the findings of Luckin (2018) regarding the concept that AI can learn from data collected, which could be why humans might perceive AI as threatening. This in turn indicates that it is important to develop the technology in close collaboration with society in order to achieve actual societal improvement, as well as prepare people for the ongoing developments.

\section{Children suffering from a long-term illness}


IJILT 38,4
The results that emerged from this study regarding investigating the specific needs of children suffering from a long-term illness and how it might affect their interaction and participation with school and friends can be compared with the results of previous research because the perceived problems have been described in various research articles (e.g. Mattsson, 1972; Enskär et al., 1997; Barakat et al., 1997; Cupit et al., 2018). However, there was one exception, namely the perceived feeling of $i$ solation. A perceived feeling of isolation concerns a feeling of being kept away from school, friends and family while being hospitalized during treatment of an illness. In this study, it could be interpreted that the special home-form housing design for sick children is reducing the perceived feeling of isolation because it offers collectivestyle living in which both children and parents meet other children and families in the same situation as themselves (cf. Cupit et al., 2018). The results that emerged from the two interviews with the AI researcher and the employee at the tech company furthered this study's understanding, constructed an understanding and provided a lot of insight into this area from another perspective. Knowledge on the current state of the field and its direction was confirmed by both the AI researcher and the tech company employee, who stated that SIAs are regarded as having almost unlimited potential but are not quite ready to be used by humans to any great extent. It could also be perceived as disheartening that the technology has not reached a point where it is capable of socially interacting with people and fulfilling their needs - for example, the specific needs of participation and interaction with the friends and school of children suffering from a long-term illness who have emerged in this study.

The quality of life of severely ill children, such as children with cancer, has only begun to be studied in recent decades because more and more children are surviving today compared to 20 years ago (Barakat et al., 1997). When we gain more knowledge about their specific needs and the problems they face, particularly regarding participation and interaction with teachers and friends at school, as well as how to meet these needs, their lives will be much healthier and improved when they recover and grow up. This could, in turn, benefit society as a whole. The societal benefits of AI today include automating mundane tasks and recognizing patterns. AI is also useful for tasks that take time and patience and that are repetitious. AI never gets tired or bored. However, the definition of a mundane task is evolving. A few decades ago, it might be screwing caps on toothpaste tubes. Today, for example, AI can drive our cars back and forth to school or work. When AI is able to manage more complex tasks, we are better able to free up time to manage the things that we cannot yet rely on machines to do. Luckin (2018) states that AI technologies cannot themselves produce a rich repertoire of intelligence available to humans. This is mainly because AI does not understand itself and cannot explain or justify its decisions; further, it has no self-awareness. However, the combination of voluminous data and well-designed AI can support us as humans in tracking the way in which our intelligence is developing (Luckin, 2018). Where the development of AI will finally end up is another discussion entirely. A question that could be asked is whether it would be societally beneficial for an SIA to help children interact with teachers and friends and participate in schoolwork when dealing with severe illness. Naturally, a child's basic needs are warmth and support from humans. However, that does not necessarily mean they cannot benefit from digital support in the form of help in explaining treatments, processing activities and encouraging the children to adopt healthy coping techniques (e.g. SIAs).

Today's children are growing up in a social reality that moves between home, school and other spaces where they meet friends; some are physical spaces and some are virtual. Giddens (1997) states that the individual and society have been connected on a global level for the first time in the history of humanity and that these changes in personal life are related to the individual's social engagement. The rapid development of new technology (e.g. AI and SIAs) and other advanced technologies (e.g. AR and VR) provides completely new opportunities for experiencing interaction and reality in new ways and mixing both the digital and physical worlds. When children are affected by a long-term illness, they are subjected to multiple 
hardships. They lose their everyday context (e.g. school) when they are hospitalized and will sometimes have to move for extended periods to another city in order be closer to specialized treatment. They struggle with questions regarding life and existential issues that are well beyond their maturity level, and there is a risk of losing out on social development. They also might have to endure difficult treatments and physical complications. The opportunity to design $\mathrm{AI}$ as truly intelligent social agents is something researchers are trying to achieve, for example, by developing ways for an SIA to build relationships and trust, cooperate dynamically with humans and work independently and freely in society. The potential for providing children with AI-based tools in order to experience what they may otherwise not have been able to experience, with the aim of providing interaction and participation for continuing their daily activities within the school context and trying to avoid a feeling of isolation, could strengthen their participation and inclusion in school activities and potentially counteract some of the negative effects of severe illness. However, current technology is limited to confined environments and specific rules. AI can take input and draw knowledge from the input, but it cannot produce more than a moderately intelligent response. Thus, building an AIbased system that will support children as a true SIA in the ways identified in this study is currently not technologically possible. However, regarding development and implementation on a smaller scale, building digital applications for assistance when children are facing illness is a concept that offers many opportunities and that has great potential. For example, as suggested by the housing manager, some kind of digital diary could potentially engage children in documenting their period of illness, and this could serve as a way of processing their emotions and retaining them as a reference for later in life. It could also be used to explain life as a hospitalized child. An AI-based SIA could help to explain treatments and their effects repeatedly to children without ever tiring or getting bored. This technology might therefore help children stay connected to their school, teachers, classmates and friends. Hence, this could prevent or reduce the feeling of isolation and, in turn, enhance their interaction and participation with their school and friends, as well as their overall quality of life when they are hospitalized.

\section{Limitations and future research}

This paper presents a pilot study conducted with the purpose of filling the gap of knowledge regarding the understanding of how AI-based SIAs might support children who suffer from a long-term illness when they have been hospitalized for extended periods with regards to interaction and participation with their school and friends. However, some limitations must be considered. For example, further research should extend the interview series to include more participants from the various areas studied: children's needs, SIAs and implementing and producing AI. Currently, experts have been interviewed. However, extending the number of participants to include children and their parents would illuminate their situations and experiences. Nevertheless, this study illustrates the challenges and proposes conceptual solutions, and we conducted it with the purpose of exploring and expanding the understanding using a holistic approach regarding experts' experiences on how AI-based SIAs might help children suffering from a long-term illness who have been hospitalized.

One methodological issue concerns the use of activity theory and the thematic analysis approach in the analysis phase. The study might have achieved different results if, for example, a more theory-driven analytical approach had been applied. However, in the analysis phase, the concepts of activity theory (Leontiev, 1986), in combination with thematic analysis (Ely, 1991), were chosen as they were useful for the purpose of the study and the research questions. This study should be regarded as an overview and an inspiration for further research, as well as an exploration of these particular issues, and it is in no way a complete knowledge resource. 
IJILT 38,4
Recommendations for future research include not only expanding the number of participants and including the perspectives of children and parents but also conducting more design-based research studies in which children and their parents have the opportunity to use and give feedback on the derived frameworks developed for AI-based SIAs. These types of studies could contribute to increasing the knowledge and broadening the understanding of how AI-based SIAs can support the needs of children suffering from a long-term illness when they have been hospitalized.

The field of AI research needs further investigation, particularly in close collaboration with users, and there is much that can be explored regarding opportunities and challenges. Not only does the technology need to be developed into systems that can manage complex social situations (i.e. the way humans interact with $\mathrm{AI}$ ), but there is also a need for developing frameworks on how to build SIAs. This can be achieved by constructing the type of AI we are currently able to build and conducting research on how humans interact with AI so as to become able to identify the simpler tasks that AI can actually perform and how it is received by humans. The third interview highlights another aspect worthy of research. This relates to how business cultures are affected when AI technology is introduced into them. Introducing a technology into a business context as something that is "new and different" (e.g. AI and SIAs) is far from a simple task, and its implications have scarcely been researched. Thus, studying what is important when implementing this is an aspect that must be considered when developing this type of technology for production (cf. Dignum, 2019), particularly from a pedagogical perspective when children are involved.

Regarding the situation of long-term illness in children, there is also a need for more research. While research has focused on studying the challenges that children face when they are ill, more research is necessary regarding what might actually support these children as far as technological adaptation is concerned when they are hospitalized. In this study, we researched the children's environment and situation. However, a deeper investigation into the psychology of children who face these challenges could increase knowledge and further the understanding of the potential that AI-based SIAs offer in improving virtual interaction and participation, as well as the overall quality of life of children suffering from a long-term illness. It is important to bear in mind that children should be allowed to take control of their own narrative - for example, focusing on children's perspectives regarding their own experiences and stated needs and values when using AI-based technology for enhancing interaction and participation in school activities. Also, it is particularly important to identify the boundaries for what is ethically sound - and the methods to identify these boundaries - before adopting any solutions that may have unexpected and undesirable consequences (Dignum, 2019). The results from this type of research regarding the use of SIAs for enhancing interaction and participation, as well as documenting everyday life, could also be transferred to situations other than hospitals in which children are virtually active together with friends or when they are alone - for example, during a pandemic when schools are closed and children receive their education in a virtual classroom in their own homes.

\section{References}

Ahmad, M.I., Mubin, O., Shahid, S. and Orlando, J. (2019), "Robot's adaptive emotional feedback sustains children's social engagement and promotes their vocabulary learning: a long-term child-robot interaction study", Adaptive Behavior, Vol. 27 No. 4, pp. 243-266, doi: 10.1177/ 1059712319844182.

Al-Gamal, E. and Long, T. (2016), "Health-related quality of life and its association with self-esteem and fatigue among children diagnosed with cancer", Journal of Clinical Nursing, Vol. 25, pp. 3391-3399, doi: 10.1111/jocn.13467. 
Amanatiadis, A., Kaburlasos, V.G., Dardani, C., Chatzichristofis, S.A. and Mitropoulos, A. (2020), "Social robots in special education: creating dynamic interactions for optimal experience", IEEE Consumer Electronics Magazine, Vol. 9 No. 3, pp. 39-45.

Anthony, S., Selkirk, E., Sung, L., Klaassen, R.J., Dix, D., Scheinemann, K. and Klassen, A.F. (2014), "Considering quality of life for children with cancer: a systematic review of patient-reported outcome measures and the development of a conceptual model", Quality of Life Research, Vol. 23 No. 3, pp. 771-789.

Bandura, A. (1982), "Self-efficacy mechanism in human agency", American Psychologist, Vol. 37 No. 2, pp. 122-147.

Barakat, L.P., Kazak, A.E., Meadows, A.T., Casey, R., Meeske, K. and Stuber, M.L. (1997), "Families surviving childhood cancer - a comparison of posttraumatic stress symptoms with families of healthy children”, Journal of Pediatric Psychology, Vol. 22 No. 6, pp. 843-859.

Belpaeme, T., Kennedy, J., Ramachandran, A., Scassellati, B. and Tanaka, F. (2018), "Social robots for education: a review", Science Robotics, Vol. 3 No. 21, available at: https://robotics.sciencemag. org/content/3/21/eaat5954.

Blusi, M. and Nieves, J.C. (2019), "Feasibility and acceptability of smart augmented reality assisting patients with medication pillbox self-management", Studies in Health Technology and Informatics, Vol. 264, pp. 521-552.

Boyatzis, R. (1998), Thematic Analysis and Code Development: Transforming Qualitative Information, Sage publication, London and New Delhi.

Breazeal, C. (2002), "Designing sociable machines - lessons learned", in Dautenhahn, K., Bond, A., Can amero, L. and Edmonds, B. (Eds), Socially Intelligent Agents - Creating Relationships with Computers and Robots, pp. 156-493.

Brown, L. and Howard, A. (2013), "Engaging children in math education using a socially interactive humanoid robot", 2013 13th IEEE-RAS International Conference on Humanoid Robots (Humanoids), pp. 183-188.

Choudhury, A., Li, H., M Greene, C. and Perumalla, S. (2018), "Humanoid robot-application and influence", Archives of Clinical and Biomedical Research, Vol. 2 No. 6, pp. 188-197.

Creswell, J.W. (2013), Qualitative Inquiry and Research Design: Choosing Among Five Approaches, 3rd ed. (updated), SAGE Publications, Thousand Oaks.

Cupit-Link, M., Syrjala, K.L. and Hashmi, S.K. (2018), "Damocles' syndrome revisited - update on the fear of cancer recurrence in the complex world of today's treatments and survivorship", Hematology/Oncology and Stem Cell Therapy, Vol. 11 No. 3, pp. 129-134.

Dautenhahn, K. (2003), "Roles and functions of robots in human society: implications from research in autism therapy", Robotica, Vol. 21 No. 4, pp. 443-452.

Dautenhahn, K., Bond, A.H., Canamero, L. and Edmonds, B. (Eds) (2002), Socially Intelligent Agents: Creating Relationships with Computers and Robots, Vol. 3, Springer Science \& Business Media, New York.

Davison, D.P., Wijnen, F.M., Charisi, V., van der Meij, J., Reidsma, D. and Evers, V. (2021), "Words of encouragement: how praise delivered by a social robot changes children's mindset for learning", Journal on Multimodal User Interfaces, Vol. 15, pp. 61-76, doi: 10.1007/s12193-020-00353-9.

Dignum, V. (2016), "Mind as a service: building socially intelligent agents", Coordination, Organizations, Institutions, and Norms in Agent Systems XI, Vol. 9628, Springer International Publishing, pp. 119-133.

Dignum, V. (2019), Responsible Artificial Intelligence: How to Develop and Use AI in a Responsible Way, 1st ed., Springer Nature Switzerland AG, Cham.

Dreyfus, H.L. and Dreyfus, S.E. (1988), Mind over Machine: The Power of Human Intuition and Expertise in the Era of the Computer, The Free Press, New York, NY.

\section{Children suffering from a long-term illness}


IJILT 38,4

D'Alfonso, S., Santesteban-Echarri, O., Rice, S., Wadley, G., Lederman, R., Miles, C., Gleeson, J. and Alvarez-Jimenez, M. (2017), "Artificial intelligence-assisted online social therapy for youth mental health", Frontiers in Psychology, Vol. 8, p. 796.

Ely, M. (1991), Doing Qualitative Research, Falmer Press, London.

Enskär, K., Carlsson, M., Golsäter, M., Hamrin, E. and Kreuger, A. (1997), "Life situation and problems as reported by children with cancer and their parents", Journal of Pediatric Oncology Nursing, Vol. 4 No. 1, pp. 18-26.

Fontana, A. and Frey, J.H. (2005), "The interview: from structured questions to negotiated test", in Denzin, N.K. and Lincoln, Y.S. (Eds), The Sage Handbook of Qualitative Research, 3rd ed., Sage Publications, pp. 695-727.

Giddens, A. (1997), Modernitet och självidentitet: självet och samhället $i$ den senmoderna epokenGöteborg: Daidalos (Modernity and Self-Identity: Self and Society in the Late Modern Era), Daidalos, Gothenburg.

Guerrero, E., Nieves, J.C. and Lindgren, H. (2016), "An activity-centric argumentation framework for assistive technology aimed at improving health", Argument and Computation, Vol. 7 No. 1 , pp. 5-33.

Halldén, G. (2003), "Barnperspektiv som ideologiskt och/eller metodologiskt begrepp (Childperspective as an ideological and or methodological concept)", Pedagogisk forskning $i$ Sverige (Pedagogical Research in Sweden), Vol. 8, pp. 12-23.

Hrastinski, S., Olofsson, A.D., Arkenback, C., Ekström, S., Ericsson, E., Fransson, G., Jaldemark, J., Ryberg, T., ÖbergFuentes, L.-M.A., Gustafsson, U., Humble, N., Mozelius, P., Sundgren, M. and Utterberg, M. (2019), "Critical imaginaries and reflections on artificial intelligence and robots in postdigital K-12 education”, Postdigital Science and Education, Vol. 1 No. 2, pp. 427-445.

Kaptelinin, V., Kuutti, K. and Bannon, L. (1995), "Activity theory - basic concepts and applications", International Conference on Human- Computer Interaction, Springer, pp. 189-201.

Kiron, D. and Unruh, G. (2019), "Even if AI can cure loneliness - should it?", MIT Sloan Management Review, Vol. 60 No. 2, pp. 1-4.

Leontiev, A.N. (1986), Verksamhet, medvetande, personlighet: Tatigkeit, Bewusstsein, Personlichkeit = Activity, Consciousness, Personality = Activité, conscience, personnalité, Progress, Moskva.

Loveys, K., Fricchione, G., Kolappa, K., Sagar, M. and Broadbent, E. (2019), "Reducing patient loneliness with artificial agents: design insights from evolutionary neuropsychiatry", Journal of Medical Internet Research, Vol. 21 No. 7, e13664.

Luckin, R. (2018), Machine Learning and Human Intelligence - The Future of Education for the 21st Century, UCL Institute of Educational Press, London.

Luxton, D. (2014), "Artificial intelligence in psychological practice: current and future applications and implications", Professional Psychology: Research and Practice, Vol. 45 No. 5, pp. 332-339.

Mattsson, A. (1972), "Long-term physical illness in childhood - a challenge to psychosocial adaptation”, Pediatrics, Vol. 50 No. 5, pp. 801-881.

Moinian, F. (2007), "Negotiating identities: exploring children's perspectives on themselves and their lives", Doctoral thesis, Teacher Education in Stockholm, Stockholm.

Mulhern, R.K., Horowitz, M.E., Ochs, J., Friedman, A.G., ArmstrongCopeland, F.D.D. and Kun, L.E. (1989), "Assessment of quality of life among pediatric patients with cancer", Psychological Assessment: The Journal of Consulting and Clinical Psychology, Vol. 1 No. 2, p. 130.

Nardi, B. (Ed.), (1996) Context and Consciousness: Activity Theory and Human-Computer Interaction, MIT Press, Cambridge.

Patton, M.Q. (1990), Qualitative Evaluation and Research Methods, 3rd ed., Sage, London.

Qvarsell, B. (2001), "Det problematiska och nödvändiga barnperspektivet (The problematic and necessary child-perspective)", in Montgomery, H. and Qvarsell, B. (Eds), Perspektiv och 
förståelse. Att kunna se från olika håll (Perspective and Understanding. To Be Able to See From Different Directions), Carlssons, Stockholm.

Serholt, S. (2017), "Child-robot interaction in education", PhD thesis, University of Gothenburg, Gothenburg.

Tegmark, M. (2017), Life 3.0: Being Human in the Age of Artificial Intelligence, Knopf, New York.

Children
suffering from
a long-term
illness

411

World Health Organization (1946), "Constitution of the World Health Organization”, available at: http://origin.who.int/about/mission/en/ (accessed 20 January 2020).

\section{Corresponding author}

Eva Mårell-Olsson can be contacted at: eva.marell-olsson@umu.se

For instructions on how to order reprints of this article, please visit our website:

www.emeraldgrouppublishing.com/licensing/reprints.htm

Or contact us for further details: permissions@emeraldinsight.com 